\title{
Readiness for Radiological and Nuclear Events among Emergency Medical Personnel
}

\author{
Cham E. Dallas ${ }^{1 *}$, Kelly R. Klein ${ }^{2}$, Thomas Lehman², Takamitsu Kodama², \\ Curtis Andrew Harris ${ }^{1}$ and Raymond E. Swienton ${ }^{2}$ \\ ${ }^{1}$ Institute for Disaster Management, University of Georgia, Athens, GA, United States, ${ }^{2}$ University of Texas Southwestern \\ Medical Center, Dallas, TX, United States
}

\section{OPEN ACCESS}

Edited by:

Steven Joseph Phillips, National Institutes of Health, United States

Reviewed by: Sofia Kottou,

National and Kapodistrian University of Athens, Greece Leonard Cole, Rutgers Medical School, United States

Pertti Juhani Hakkinen, United States National Library of Medicine $(\mathrm{NIH})$, United States

*Correspondence: Cham E. Dallas cdallas@uga.edu

Specialty section:

This article was submitted to Disaster and Emergency Medicine,

a section of the journal Frontiers in Public Health

Received: 26 April 2017 Accepted: 24 July 2017

Published: 18 August 2017

Citation:

Dallas CE, Klein KR, Lehman T, Kodama T, Harris CA and Swienton RE (2017) Readiness for Radiological and Nuclear

Events among Emergency Medical Personnel.

Front. Public Health 5:202. doi: 10.3389/fpubh.2017.00202
Background: Among medical providers, even though radiological and nuclear events are recognized as credible threats, there is a lack of knowledge and fear about the medical consequences among medical personnel which could significantly affect the treatment of patients injured and/or contaminated in such scenarios. This study was conducted to evaluate the relative knowledge, willingness to respond, and familiarity with nuclear/radiological contamination risks among U.S. and Japanese emergency medical personnel.

Methods: An institutional review board-approved anonymous paper survey was distributed at various medical and disaster conferences and medicine courses in Japan and in the U.S. The surveys were written in Japanese and English and collected information on the following four categories: generalized demographics, willingness to manage, knowledge of disaster systems, and contamination risks.

Results: A total of 418 surveys were completed and collected. Demographics showed that physicians and prehospital responders were the prevalent survey responders. The majority of responders, despite self-professed disaster training, were still very uncomfortable with and unaware how to respond to a radiological/nuclear event.

Conclusion: Despite some educational coverage in courses and a limited number of disaster events, it is concluded that there is a lack of comfort and knowledge regarding nuclear and radiological events among the medical community. It is recommended that considerable development and subsequent distribution is needed to better educate and prepare the medical community for inevitable upcoming radiological/nuclear events.

\section{Keywords: radiation, radiological, nuclear warfare, emergency medical services, risk assessment}

\section{INTRODUCTION}

In the disaster community, born out by recent events such as the Fukushima nuclear power plant incident, there is an increasingly recognized concern that emergency medical personnel will have to care for patients injured or contaminated by radioactive material in the aftermath of a nuclear or radiological event (1). Along with this concern is the widespread perception that clinicians are not properly educated and trained for radiological and nuclear events; and in many cases, the clinicians do not have the confidence, or the knowledge, in existing response and treatment protocols in the 
event of the need for a radiological response (2). Indeed, it has been noted that in the case of a potential nuclear attack, there is a sense of nihilism concerning the effectiveness of a medical response to the extent that civilian medical response planning is limited (3).

Despite perceived deficiencies in planning and preparedness for nuclear and radiological events, there is recognition that these events are increasingly likely to occur (4-6). Nuclear power accidents and nuclear detonations have resulted in mega mass casualty events with devastating acute and long-term injuries (7). Indeed, the Chernobyl nuclear accident produced the largest number of documented radioactively contaminated casualties, including scores of deaths (8). However, the major concern is for future intentional releases of radiological materials, including surveys of expert panels that have identified terrorism involving radioactive materials as one of the most likely threats for the U.S. $(2,9)$. With increasing international tensions and the consistent proliferation of nuclear weapons in less-stable states, the potential for the devastating impact of nuclear weapons makes an understanding of the medical consequences of radiological and nuclear events even more strikingly important $(5,10)$.

Surveys of medical personnel in recent years have indicated a concern for the level of preparedness for various components of weapons of mass destruction, as they are outside of normal practice experience. Most of these studies have dealt with concerns for biological or chemical agents, with definitive deficiencies identified, particularly reluctance of medical personnel to participate in the midst of the crisis (11-13). Relatively few studies have dealt with these issues with radiological agents, and those that have been conducted definitively indicate a need for further investigation due to fear and lack of knowledge $(2,14)$.

\section{MATERIALS AND METHODS}

The current investigation involved an institutional review board (IRB)-approved survey (Figure 1) disseminated to hundreds of emergency medical personnel to evaluate their clinical care knowledge regarding radiological exposure and/or injury. Specific perceptions such as willingness to practice during a radiological crisis, decontamination needs of patients, and risks of exposure to the medical provider were also queried. The written survey was administered in two languages, Japanese and English, and conducted in Japan and the U.S. The Japanese translation was provided by a Japanese medical provider who is fluent in English.

The conferences and courses were selected with the intent to best ensure participation of those medical personnel who actually respond clinically in emergencies. Anonymous paper surveys distributed at various Japanese and U.S. conferences and courses were collected from a total of 418 medical personnel who chose to fill out and return them. The survey was devised in a series of meetings by the authors with subject matter expertise in emergency medicine and toxicology and field experience in environmental radiation exposure. The resulting survey received IRB approval from the University of Texas Southwestern Medical School at Dallas. Confidentiality was maintained for all participants as the surveys did not have details of contact information and were gathered on mass, and none of them received payment or any other incentives to participate. The group conducting the survey is a part of the Nuclear Radiological Disaster Casualty Management (NRDCM) Workgroup. The stated goal of the NRDCM to the participants was "The NRDCM Global Initiative is a multi-national collaboration to improve our global and country-specific preparedness and response in managing the casualties from nuclear and radiological disasters. This initiative is focused upon identifying and improving the concepts, principles, and methods to prepare health professionals and the public for clinical management of casualties during nuclear and radiological disasters and the resulting public health emergencies."

\section{RESULTS}

\section{Demographics}

Demographic analysis of the 418 participants completing the survey identified that $60 \%$ of respondents were male and $40 \%$ were female. Of the respondents, 206 were Japanese and a small number of them were from other Asian countries (hereafter referred to as Japanese), and 212 were from the U.S. Approximately 1,200 surveys were handed out, so that the response rate was about $35 \%$. A total of $0 \%$ of the participants were radiation specialists, $6.5 \%$ were involved with public health primarily, $10.5 \%$ were EMS (paramedic/EMT), 21\% were nurses, and 50.5\% were physicians of varying background. A total of $5 \%$ of the participants stated that they worked primarily in the radiation and/or nuclear science field (not medical). Additionally, $40 \%$ indicated that they have been involved in a disaster (36\% Japanese and 44\% U.S.), and $33.5 \%$ had been affiliated with a disaster response team. There is a much greater affiliation of Japanese with these organized teams, at $42.7 \%$, than for the U.S. at $24.5 \%$. In relation to actual emergency scene response experience, $40 \%$ have been to an emergency response scene (35.9\% Japanese and $43.9 \%$ U.S.) and $66 \%$ were willing to be a part of an emergency scene (54.9\% Japanese and $77.4 \%$ U.S.). In relation to the number of actual courses taken with specific radiological and/or nuclear content; over half (56\%) had never taken a single course, approximately a quarter had taken one course, $14.4 \%$ had taken two to four courses, and only $3.3 \%$ had taken five or more courses (Figure 2).

\section{Willingness to Manage Exposed Casualties}

In Figures 3-5, a score of 1-5 was employed with respondents asked to assign a rank with " 1 " as the most important and " 5 " as the least important. When the respondents were asked to rank what they thought would be the most immediate medical needs after a nuclear detonation, the highest ranking was given to thermal burns, followed by crush syndrome, radiation sickness, lacerations, and psychological trauma, in a steadily decreasing order (Figure 3). The results were remarkably similar between Japanese and U.S. survey respondents for thermal burns, crush syndrome, and radiation sickness. Japanese respondents were more likely to consider lacerations as a more immediate need than those from the U.S., and less likely to consider psychological trauma as an immediate need than U.S. respondents. For the survey question "which disaster type would make them unwilling to come to 


\section{Research Question:}

\section{Please Complete this Approved Research Survey}

In the past 30 years there have been multiple radiological and nuclear events that have occurred throughout the world. This short IRB approved anonymous survey is gathering data to see if health care professionals are both willing and knowledgeable to care for victims of radiological and nuclear events. Please be as honest as possible as your answers will begin to guide the future medical disaster approach to these events. The writers of this survey are an international work group dedicated to the improvement of disaster casualty management. The survey should take approximately 7 minutes.

\section{When you are finished, please place in designated boxes. Thank you very much for your participation!} SURVEY STARTS below (Please note that the questions are on both sides of the paper)

\begin{tabular}{|c|c|c|}
\hline Item & Question to Answer & Selection Choices \\
\hline 1 & $\begin{array}{l}\text { In the event of a large-scale medical emergency, people are } \\
\text { often scared and fearful. Please rank the following events in } \\
\text { that may prevent you from coming to work. } \\
\text { Please Rank in order of importance to you, using numbers 1-5. } \\
\text { Use \# } 1 \text { as MOST important to you, and \# } 5 \text { is LEAST. } \\
\text { Please do NOT repeat numbers. }\end{array}$ & $\begin{array}{l}\text { Rank \# } 1 \text { as MOST important, and rank \# } 5 \text { as LEAST regarding disaster types } \\
\text { that may prevent you from coming to work: } \\
\text { —. Biological disaster such as "Bird Flu" H1N1 or smallpox } \\
\ldots \text { - Chemical disaster such as nerve agents like Sarin, Tabun, or VX } \\
\ldots \text {. Radiological disaster such as a dirty bomb explosion } \\
\ldots \text { - Nuclear disaster such as a nuclear bomb detonation } \\
\ldots \text {. Nuclear disaster such as a nuclear power plant catastrophe }\end{array}$ \\
\hline 2 & $\begin{array}{l}\text { Would you be willing to be part of a scene response to treat } \\
\text { casualties where there might be radiation or nuclear material } \\
\text { contamination? Please circle ONE of the following choices }\end{array}$ & YES | NO \\
\hline 3 & $\begin{array}{l}\text { Would you be willing to treat casualties at your hospital, if } \\
\text { only their clothes had been removed after being exposed to } \\
\text { radiation or nuclear material contamination? } \\
\qquad \text { Please circle ONE of the following choices }\end{array}$ & YES | NO \\
\hline 4 & $\begin{array}{l}\text { If in the event of a nuclear detonation what would make you } \\
\text { willing to go to work? } \\
\text { Please Rank in order of importance to you, using numbers 1-5. } \\
\text { Use \# } 1 \text { as MOST important to you, and \# } 5 \text { is least. } \\
\text { Please do NOT repeat numbers. } \\
\text { NOTE: Ifyou are not willing to go to work regardless, } \\
\text { then select this option, and do not rank items. }\end{array}$ & 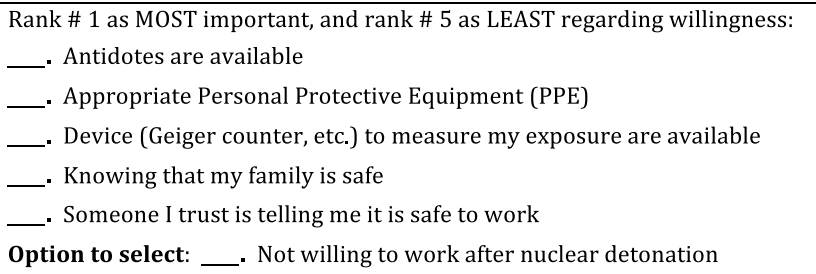 \\
\hline 5 & $\begin{array}{l}\text { Rank what you feel will be the acute medical needs in the } \\
\text { hours following a nuclear detonation } \\
\text { Please Rank in order of importance to you, using numbers 1-5. } \\
\text { Use \# } 1 \text { as MOST important to you, and \# } 5 \text { is LEAST. } \\
\text { Please do NOT repeat numbers. }\end{array}$ & $\begin{array}{l}\text { Rank \# } 1 \text { as MOST important, and rank \# } 5 \text { as LEAST important: } \\
\text { —. Acute Radiation Sickness (ARS) } \\
\text { —. Burn (Thermal) injuries } \\
\text { —. Crush injuries from collapsed buildings } \\
\text { —. Lacerations from broken glass } \\
\ldots \text {. Psychological trauma and behavioral illnesses }\end{array}$ \\
\hline
\end{tabular}

\begin{tabular}{|c|c|c|}
\hline Item & Question to Answer & Selection Choices \\
\hline 6 & $\begin{array}{l}\text { How familiar are you with disaster response teams in your } \\
\text { country? } \quad \text { Please circle ONE of the following choices }\end{array}$ & NOT FAMILIAR | SOMEWHAT FAMILIAR | VERY FAMILIAR \\
\hline 7 & $\begin{array}{l}\text { What disaster teams are present in your country? } \\
\text { Circle ALL that apply }\end{array}$ & NONE | DMAT | MERT | MILITARY | UNSURE | OTHER \\
\hline 8 & $\begin{array}{l}\text { Are you on a disaster response team in your country? } \\
\text { Please circle ONE of the following choices }\end{array}$ & YES | NO If you answer YES, please write team name: \\
\hline 9 & $\begin{array}{l}\text { Have you ever been involved with or responded to a natural } \\
\text { disaster or public health emergency? } \\
\qquad \text { Please circle ONE of the following choices }\end{array}$ & YES | NO \\
\hline
\end{tabular}




\begin{tabular}{|c|c|c|}
\hline Item & Question to Answer & Selection Choices \\
\hline 10 & $\begin{array}{l}\text { In all of the radiological/nuclear events since World War II } \\
\text { about how many healthcare providers have been made sick } \\
\text { or been put at risk from treating patients contaminated with } \\
\text { radiological material? } \\
\qquad \text { Please circle ONE of the following choices }\end{array}$ & 0 Providers | 1 Provider | $\mathbf{1 0}$ Providers | 100 Providers | Do Not Know \\
\hline 11 & $\begin{array}{l}\text { How many nuclear/radiological response/treatment courses } \\
\text { have you completed? } \\
\qquad \text { Please circle ONE of the following choices }\end{array}$ & 0 Courses | $\mathbf{1}$ Course | 2-4 Courses | $\mathbf{5}$ or more Courses completed \\
\hline 12 & $\begin{array}{l}\text { A patient arrives with a trauma emergency and burn injuries } \\
\text { following a nuclear detonation. Before beginning care what } \\
\text { type of decontamination is needed? } \\
\text { Please select ONE of the following choices }\end{array}$ & 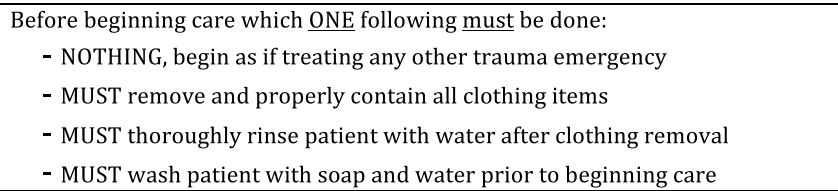 \\
\hline 13 & $\begin{array}{l}\text { A patient arrives with a trauma emergency and burn injuries } \\
\text { following a nuclear detonation. Before beginning care what } \\
\text { is the best Personal Protective Equipment (PPE) for you } \\
\text { and staff to wear? } \quad \text { Please circle ONE of the following } \\
\text { choices }\end{array}$ & Level A | Level B | Level C | Level D | Do Not Know \\
\hline 14 & $\begin{array}{l}\text { You are taking care of a trauma patient who has ingested or } \\
\text { inhaled radioactive substances. Please estimate your risk of } \\
\text { serious radioactivity exposure? } \\
\text { Please circle ONE of the following choices }\end{array}$ & HIGH | MODERATE | LOW | NO Risk | Do Not Know \\
\hline
\end{tabular}

\begin{tabular}{|c|c|c|}
\hline Item & Question to Answer & Response Selection Choices \\
\hline 15 & $\begin{array}{l}\text { What is the year of your birth? } \\
\text { Please write in your response }\end{array}$ & My YEAR of birth is: \\
\hline 16 & $\begin{array}{l}\text { What is your gender? } \\
\qquad \text { Please circle ONE of the following choices }\end{array}$ & MALE | FEMALE \\
\hline 17 & $\begin{array}{l}\text { What is your country of medical practice? } \\
\text { Please write the name of your country }\end{array}$ & My country name is: \\
\hline 18 & $\begin{array}{l}\text { What is your highest education degree? } \\
\qquad \text { Please circle ONE of the following choices }\end{array}$ & UNDERGRADUATE | GRADUATE | DOCTORATE (MBBS, MD/DO, PhD, DVM) \\
\hline 19 & $\begin{array}{l}\text { What is your type of medical practice? } \\
\qquad \text { Please circle ONE of the following choices }\end{array}$ & CLINIC | HOSPITAL | UNIVERSITY | RETIRED | OTHER_ \\
\hline 20 & $\begin{array}{l}\text { Are you in the military (active or reserve)? } \\
\qquad \text { Please circle ONE of the following choices }\end{array}$ & YES I NO I RETIRED \\
\hline 21 & $\begin{array}{l}\text { Do you work in the radiation/nuclear science field? } \\
\text { Please circle ONE of the following choices }\end{array}$ & YES I NO \\
\hline 22 & $\begin{array}{l}\text { What is your current occupation or primary training? } \\
\text { Please circle ONE from the following table }\end{array}$ & Circle your PRIMARY TRAINING area/ discipline from the table below: \\
\hline
\end{tabular}

\begin{tabular}{|l|l|l|}
\hline Surgeon & General Medicine & Critical Care \\
\hline Emergency Medicine & Pediatrics & Public Health \\
\hline Radiology & Family Practice & Anesthesia \\
\hline OB-GYN & Orthopedics & Nurse \\
\hline Psychiatry & EMT/Paramedic & Radiation Specialist \\
\hline Other: & \multicolumn{2}{|l}{} \\
\cline { 1 - 2 } & &
\end{tabular}

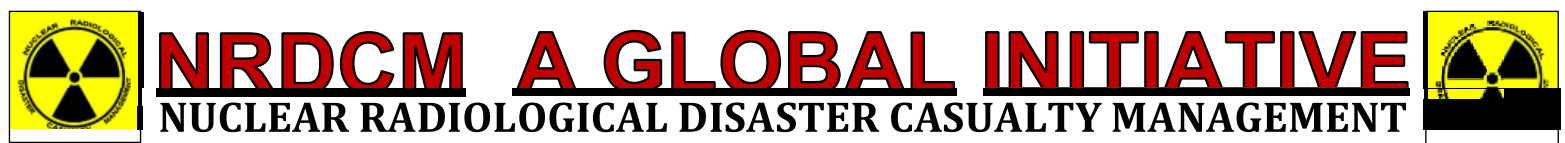

FIGURE 1 | Nuclear Radiological Disaster Casualty Management Nuc-Rad Survey (English version). 


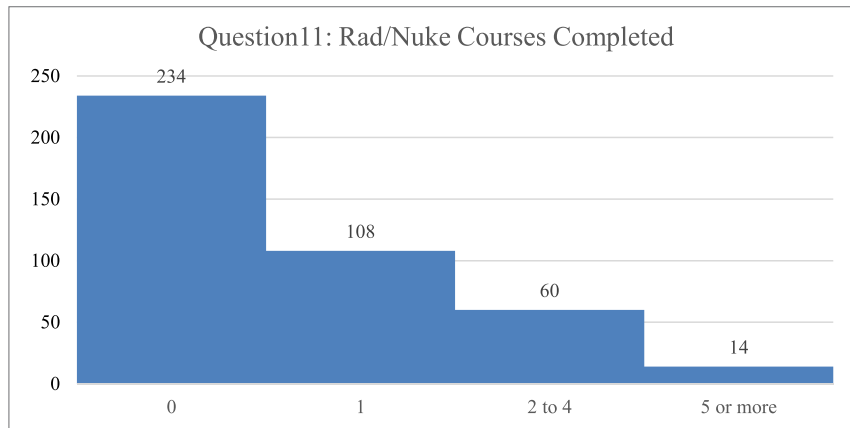

FIGURE 2 | The number of formal courses concerning radiological or nuclear issues taken previously by the respondents is categorized, left to right, as 0 , $1,2-4,5$, or more courses with the majority of respondents having not taken any courses.
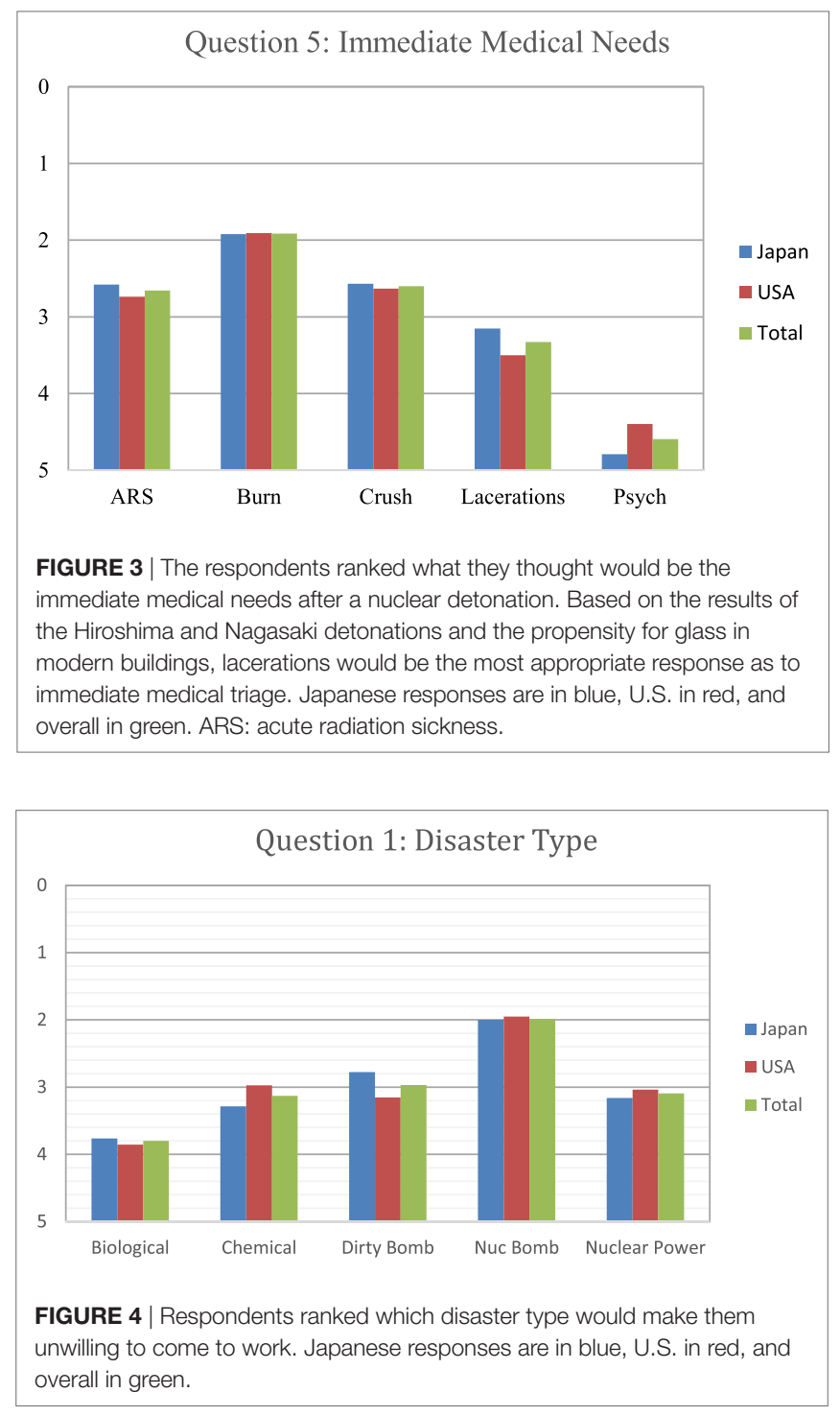

work," respondents from both countries selected nuclear bomb by a wide margin over all other options (Figure 4). Overall, results for the dirty bomb, chemical, and nuclear power plant disaster

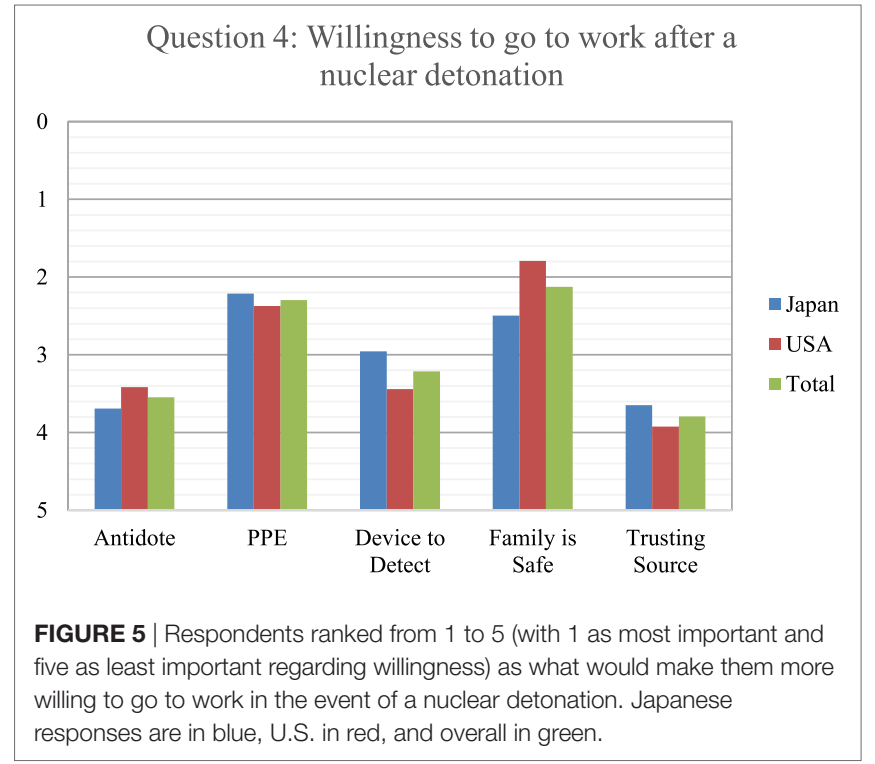

options were all essentially equivalent in rank, although far below the nuclear bomb disaster. However, Japanese respondents were $27 \%$ more likely than U.S. respondents to consider a dirty bomb scenario to make them unwilling come to work. Interestingly, the respondents were the least likely to consider biological events as the type of event to make them unwilling to come to work. Indeed, they ranked nuclear bomb as 2.5 times more likely to influence them than biological event.

With an understanding that clinical providers are less likely to show up for work following a nuclear disaster, respondents were asked to rank on the 1-5 scale (with 1 as most important and 5 as least important regarding willingness) what information they would need or equipment/medications they could possess that would influence them to change their minds. Respondents indicated that trusting the source of information was least important to them, followed closely by having an antidote on hand (Figure 5 ). The next least effective factor was having equipment available to detect the radioactivity, with U.S. respondents ranking detection equipment lower than the Japanese. Of much greater importance was personal protective equipment (PPE), with the perception that their families were safe. However, knowing that the family was safe was $24.6 \%$ more important to U.S. respondents than Japanese. Indeed, knowing that their family was safe was the most important of the five options available to the U.S. respondents to increase willingness to work after a nuclear detonation.

The respondents provided interesting findings as to their relative perceptions of radioactively exposed patients. When respondents were asked "Would you be willing to be part of a scene response to treat casualties where there might be radiation or nuclear material contamination?" $66 \%$ said yes, while $33 \%$ said no. When the conditions of treatment were further specified with the question, "Would you be willing to treat casualties at your hospital, if only their clothes had been removed after being exposed to radiation or nuclear material contamination?" The majority of respondents (79.4\%) would, with $82 \%$ of U.S. respondents and $76.7 \%$ of Japanese respondents. 


\section{Familiarity with Nuclear/Radiological Contamination Risks}

In an evaluation of relative nuclear/radiological contamination risks, the respondents indicated what type of patient decontamination they perceive is needed following contamination with radiological particles (Figure 6). This was measured by the respondents giving one of the four answers to the question, "A patient arrives with a trauma emergency and burn injury following a nuclear detonation. Before beginning care what type of decontamination is needed (must be done)?" The preferred decontamination approach in the survey from the total respondents was to remove and properly contain all clothing items, followed by rinsing the patient with water. However, the Japanese respondents were far more likely to prefer this approach than the U.S. respondents. The least popular choice was to do nothing and treat the contaminated patient like any other trauma patient.

In addressing the type of PPE needed for radioactive contamination, over $37 \%$ of the respondents indicated that they did not know what to use and declined to pick from one of the four (Level A-D) PPE levels (Figure 7). The Japanese (61\%) were much more likely to state this than the U.S. respondents (15\%). At least partly due to the relatively higher response rate of making a decision, the U.S. respondents had higher response rates than the Japanese for Level B (17 versus 5\%), Level C (31 versus 13\%), and Level D (18 versus $7 \%$ ), respectively.

Of the levels that were selected, the first choice was Level C with $22 \%$, followed by Level A with $16 \%$, Level D with $13 \%$, and Level B with 11\%. An assessment of health-care responder safety perception with regard to treating a patient who either had been exposed or contaminated by radiation was investigated, by asking respondents to indicate how many health-care

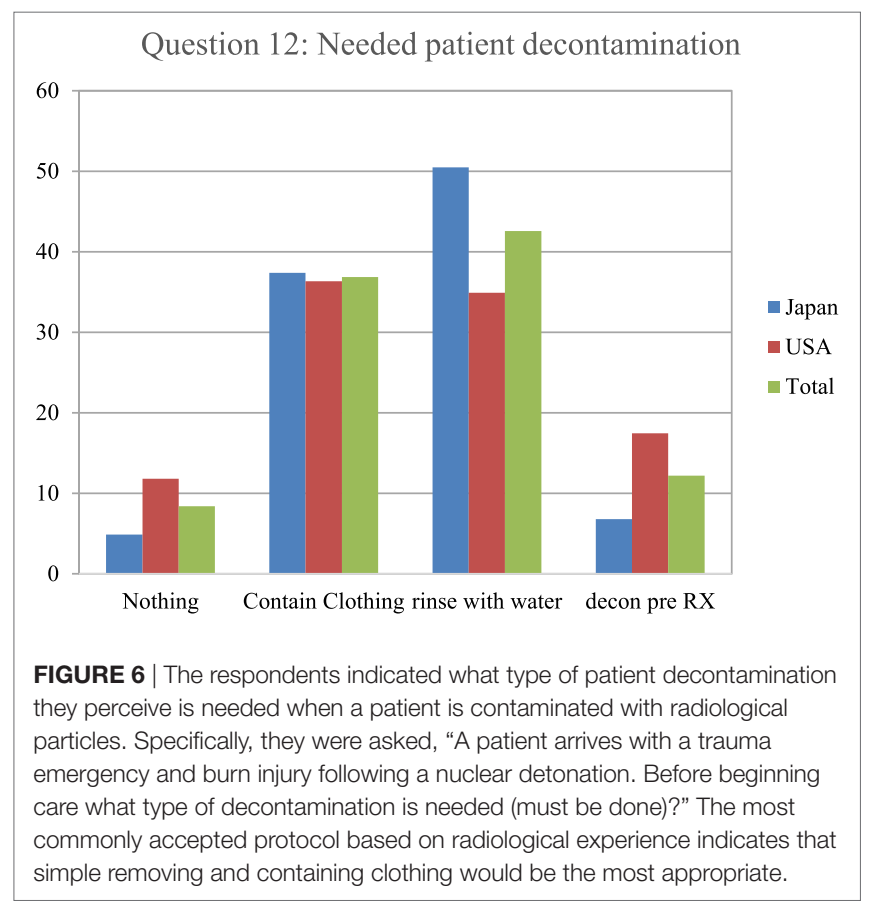

providers they thought had been made sick or been put at risk from treating patients contaminated with radiological material since World War II (Figure 8). As with the risk question with PPE, $71 \%$ of respondents indicated that they did not know. Of the few responding that chose an answer besides don't know, $11 \%$ picked 100 providers getting ill from treating radioactively contaminated patients, followed by $10 \%$ picking 0 , and $6 \%$ answering that 10 providers had become ill. Finally, respondents were asked to indicate the perception of their own relative risk in treating patients with internal radioactive contamination, ranging from unknown, no risk, low, medium, and high risk (Figure 9). While approximately a quarter of the respondents indicated that they did not know, $27.5 \%$ reported a perception of low risk, followed by $21 \%$ indicating moderate risk, $13 \%$ assuming high risk, and only $11 \%$ indicating no risk. In comparison between Japanese and U.S. respondents, 39\% of the Japanese said that they did not know while $39 \%$ of U.S. respondents assumed a low level of risk.

\section{DISCUSSION}

It is widely acknowledged in the security industry that the threat of using at least one nuclear weapon is steadily increasing, and while historically rare, the sheer volume of people impacted by the release of radiological materials following the nuclear reactor meltdowns at Chernobyl and Fukushima, as well as the nuclear bomb detonations in Nagasaki and Hiroshima, have highlighted the importance of knowledge, expertise, and training for an appropriate emergency medical response. For a multitude of reasons, a major radiological event, from a nuclear plant meltdown,

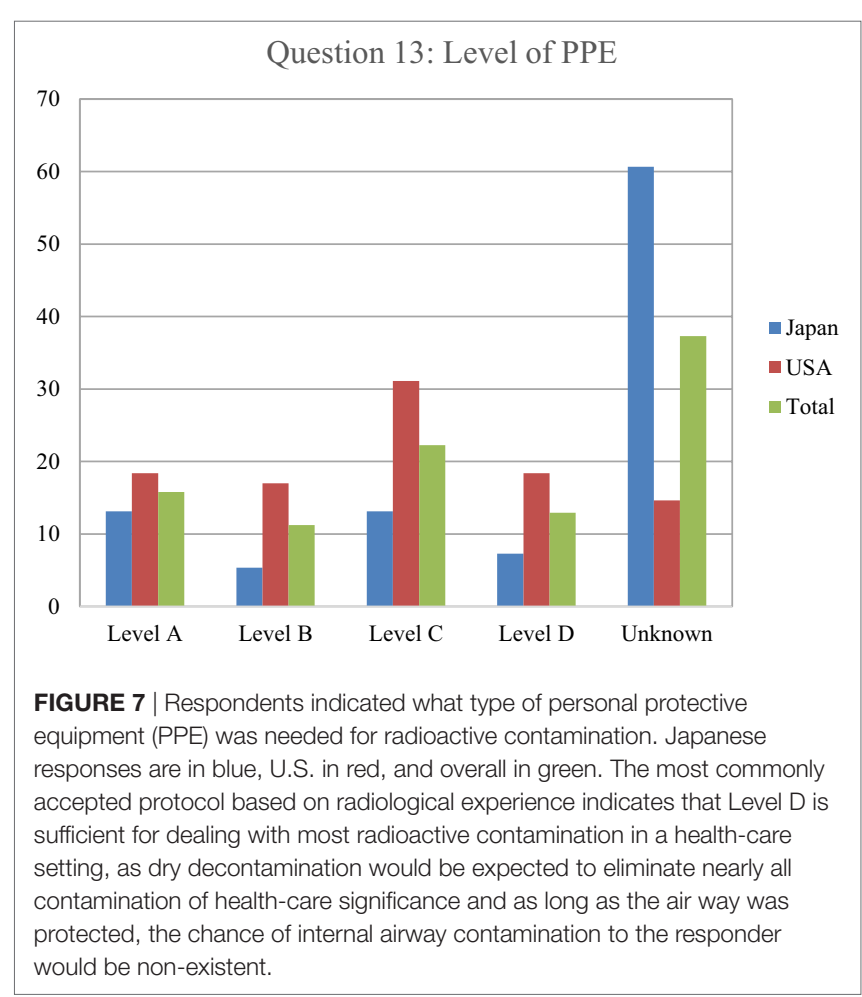




\section{Question 10: Healthcare Provider Risk of Radiological Contamination}

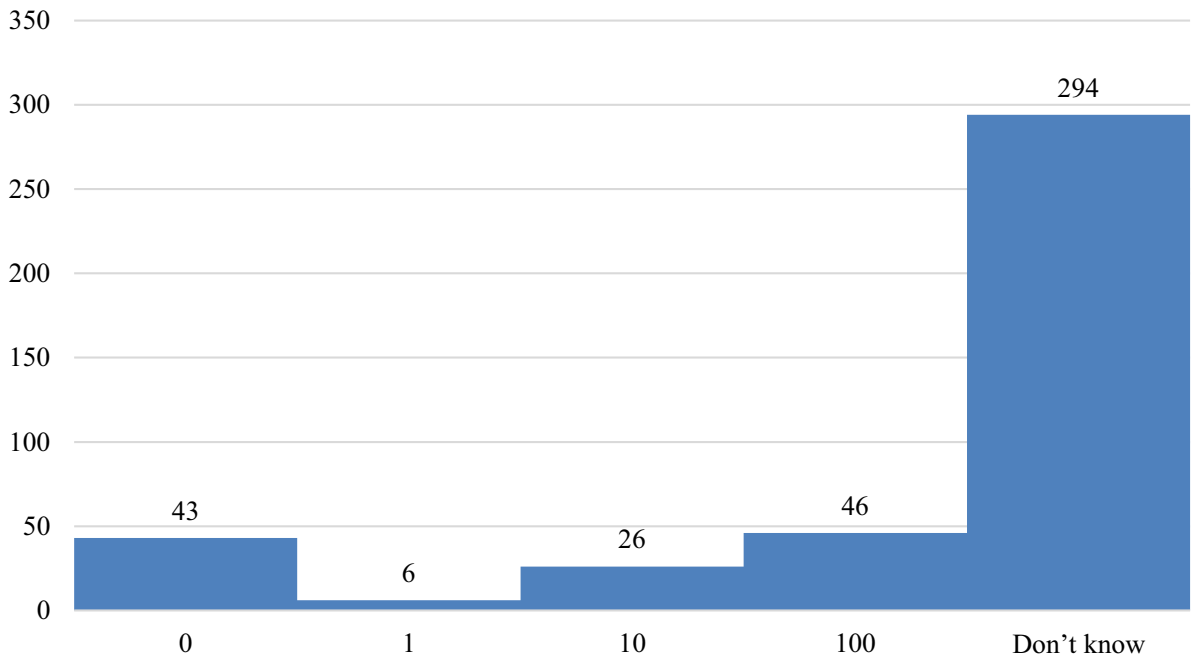

FIGURE 8 | Respondents indicated how many health-care providers that they thought had been made sick or been put at risk from treating patients contaminated with radiological material since World War II. The number of respondents is indicated for each of the following answers: 0 , 1, 10, 100, and Don't Know. The most appropriate answer is 0 from all published evidence reviewed.

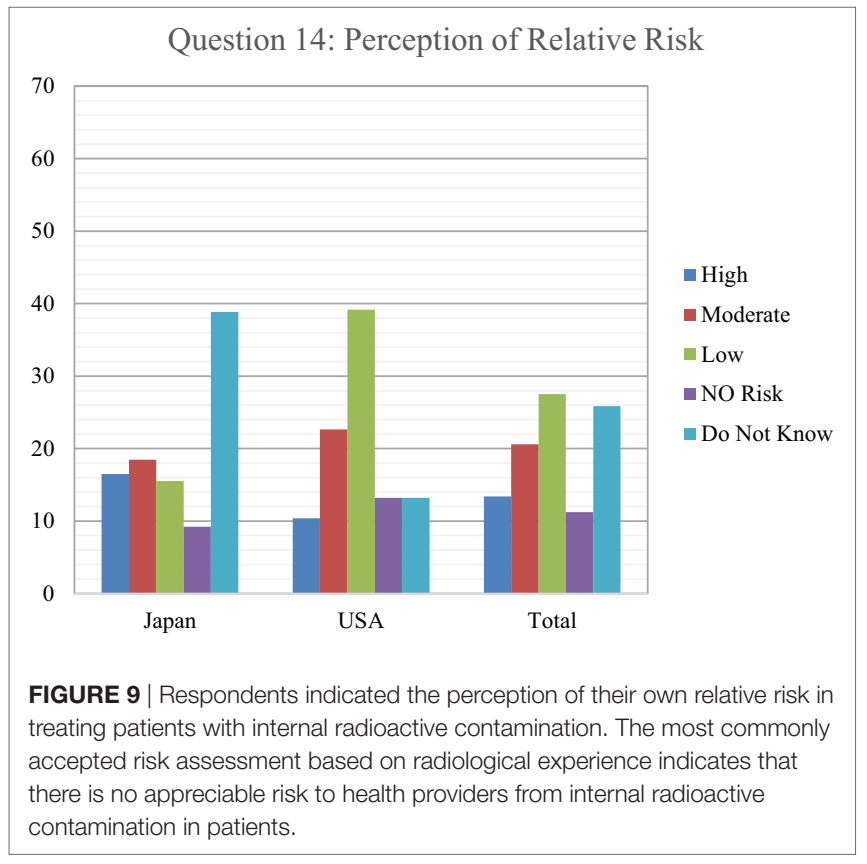

intentional dissemination of high-level radiological materials in the environment, or the use of a nuclear weapon, will immediately provoke an unprecedented public health emergency. This will included those directly affected during the event, as well as the worried well who are far removed but fearing the worst. It is a known fact that there are over 16,000 nuclear weapons worldwide today, and the number of nations possessing nuclear weapons and nuclear power plants are steadily increasing (7).
The infrequent appearance of radioactive materials in the environment and the lack of use of any nuclear weapons in warfare for over 70 years have, despite the recent history of Fukushima, resulted in a steady decline in interest and in the training of medical personnel prepared to treat casualties from nuclear and radiological events in civilian institutions. Specific high-level expertise now remains in very few military or civilian sectors. This is especially evident in the field of medicine, where radiation expertise is almost exclusively related to training and proactive with therapeutic regimens, under tightly controlled conditions, but for large scale exposures or contamination is not well understood or taught (15). Among the general population of medical and public health personnel, there is a paucity of training and understanding of the health effects and accepted protocols for appropriate response to effects generated by environmental radioactivity, a very different set of skills and knowledge than that which exists for clinical approaches with radiation.

Studies have shown that for a biological outbreak, as seen with SARS, medical personnel would come to work and provide medical care if they felt safe. However, for a radiological incident, as seen in the aftermath of Fukushima, there are indications that medical personnel might have an unwillingness to respond to unusual emergency conditions with which they are not familiar, and consider dangerous. This is supported by our survey from both the U.S. and Asia where respondents, definitively selected nuclear events as the most likely to discourage them from coming to work, closely followed by radiological and chemical events. Indeed, nuclear events were 2.5 times as likely as biological events to discourage them from accomplishing their medical or other critical duties in a crisis. This finding is in strong dichotomy from the general consensus among experts in assessing radiation risk that with minimal precautions there 
is relatively little danger to medical personnel from radioactive contaminants $(1,16)$. This lack of knowledge of relative risk among medical personnel in the U.S. and Asia was further clarified by the fact that $90 \%$ of the survey respondents were unaware that there is not a single recorded instance of a medical provider for radioactively contaminated personnel ever being injured by providing treatment. However, it was encouraging to see that despite this deficiency, $82 \%$ of U.S. respondents and $76.7 \%$ of Japan respondents said that they would still treat patients if at least their clothing had been removed.

Regional nuclear arms races are now of great concern, as the addition of nuclear weapons to antagonistic neighbors with a consistent track record of repeated non-nuclear conflicts seem certain of dramtically escalating the consequences of these familiar conflicts. After India had become a nuclear power in 1974, India and Pakistan both escalated their nuclear weapons development, resulting in public displays of nuclear tests in 1998. There is widespread fear and suspicion of the increasingly unstable nature of Pakistan and in particular there is definite concern for its ability to secure its steadily increasing nuclear weapons (5-10 new weapons every year) and protect the stored weapons from theft. Indeed, there is an accelerating nuclear arms race now in the Middle East and East Asia, with the staggering potential for medical casualties from their use in regional nuclear conflicts described in recent studies $(10,17)$. However, just as concerning is the threat of a dirty bomb (explosive device surrounded by radioactive materials) or crude radioactive dispersal devices $(18,19)$. The real hazard of dirty bombs is not actually related to lethality other than the explosives and is generally not expected to result in significant radiation-induced casualties. However, the terror and fear induction capability of a dirty bomb or some other dispersal of radioactive materials could be of considerable magnitude. In the current survey, fear of the consequences of exposure to patients in the aftermath a dirty bomb was considerably less than that for a nuclear event. One of the more definitive differences between Japanese and U.S. respondents was that Japanese respondents were $27 \%$ more likely to not come to work in a dirty bomb scenario than U.S. respondents.

Despite this inadequate acknowledgment of the importance of radiological/nuclear threats and knowledge, this lack of adequate health-care resources will still be a significant consideration for responding to even the smaller nuclear weapon detonations. Despite the importance of this issue, there are still very few references to the tragic consequences of the inadequacy of the likely response that will occur for nuclear weapon use, reflective of the widespread pattern of denial for this issue. The primary injury types that would be expected to result for an urban nuclear detonation are trauma, thermal burn, and radiation (4). In all three categories, the resulting massive numbers of casualties will certainly be expected to result in a nearly complete insufficiency in health-care response (which of course is related to the serious denial in the health-care community). Additionally, the fortunate lack of radioactive events which has resulted in little to no experience with environmental radioactivity for most medical providers becomes particularly problematic for treatment $(19,20)$. For instance, in the current study, $37.3 \%$ of all respondents did not know what PPE to use to protect them when encountering radiologically contaminated patients.

Despair and denial has often been the outcome of the consideration of high casualty assumptions for nuclear war associated with planners and providers for mass casualty medical response (21). One very unfortunate, and frankly unacceptable, perception that usually results is that planning and response for nuclear war are therefore not productive. However, in this study, one-third of the participants indicated that they would not condone their participation in an emergency response involving the handling of casualties with the possibility of radioactive contamination at any level. However, nuclear warfare has many variants, and there are many scenarios that can have effective planning that would enable the rational use of available resources that would save many lives and significantly reduce suffering (22). The Rad Resilient City Initiative (23) has provided a cogent system toward this end, including fallout protection assessment, pre-incident public education, establishing a rapid system for mapping fallout, developing capabilities to support large-scale evacuation, and training for these elements. The advantages of making these efforts are even more fruitful in response to the relatively smaller nuclear weapons. Therefore, since the education of the medical and public health community now has scenarios involving radiation contamination that show a lack of danger to them as providers, this should diminish this significant reluctance to participate in any medical treatment involving environmental radiation.

This need for medical education related to the myths and realities of environmental radioactivity is even more critical in recognition that the consistent pattern of the concentration of hospitals, clinics, and medical personnel in urban areas, particularly the central zones, will result in a disproportionate loss of medical resources in a nuclear attack $(6,24)$. Because of the concentration of health-care facilities in downtown urban areas across the U.S., it was concluded in a National Academy of Sciences study (22) that over half of all hospital beds in U.S. cities would not be expected to be accessible at all the most likely anticipated nuclear attacks. For instance, a study of the potential for medical and personnel resources to be available following a nuclear attack on London concluded that less than $20 \%$ of hospital beds would be accessible, with some 150 candidates for each bed (25). It should be noted that valuable education in this area are available using downloaded documents, online teaching, recorded webcasts, video tutorials, and teaching via web sites (25-27). In the larger high-consequence events, not limited to nuclear weapon events, it is also likely that there will simply not be enough health-care workers, even with Herculean efforts with widespread ancillary health-care personnel. Therefore, we cannot afford to lose a large portion of the surviving medical responding population in a nuclear attack, already insufficient to the needed response, to an unwarranted and uneducated fear of the consequences of radiation exposure.

\section{CONCLUSION}

Despite the acknowledgment by experts that a radiological or nuclear incident is inevitable, the health-care community is 
not comfortable, knowledgeable, or prepared to deal with the contaminated or exposed patient. More research as to what needs to be taught resulting in meaningful training needs to be developed.

\section{ETHICS STATEMENT}

The UT Southwestern Institutional Review Board (IRB) determined on November 18, 2013, that this research is exempt in accordance with 45 CFR 46.101(b). Further review of this study by the IRB is not required unless the protocol changes in the use of human subjects.

\section{REFERENCES}

1. Bushberg JT, Kroger LA, Hartman MB, Leidholdt EM Jr, Miller KL, Derlet R, et al. Nuclear/radiological terrorism: emergency department management of radiation casualties. J Emerg Med (2007) 32(1):71-85. doi:10.1016/j.jemermed.2006.05.034

2. Becker SM, Middleton SA. Improving hospital preparedness for radiological terrorism: perspectives from emergency department physicians and nurses. Disaster Med Public Health Prep (2008) 2(3):174-84. doi:10.1097/ DMP.0b013e31817dcd9a

3. Coleman CN, Hrdina C, Bader JL, Norwood A, Hayhurst R, Forsha J, et al. Medical response to a radiologic/nuclear event: integrated plan from the Office of the Assistant Secretary for Preparedness and Response, Department of Health and Human Services. Ann Emerg Med (2009) 53(2):213-22. doi:10.1016/j.annemergmed.2007.12.021

4. Dallas CE, Maliha W, Reeves GI, White JC, Lyznicki J, Bell W. Chapter 7: Nuclear and radiological disasters. In: Swienton R, Subbarao I, Markenson D, editors. Basic Disaster Life Support (BDLS v.3.0), American Medical Association (2012). p. 7-1-45.

5. Hellman ME. Risk Analysis of Nuclear Deterrence. The Bent of Tau Beta Pi, Spring (2008). p. 14-22.

6. Bell WC, Dallas CE. Vulnerability of populations and the urban health care systems to nuclear weapon attack - examples from four American cities. Int J Health Geogr (2007) 6(5):1-33. doi:10.1186/1476-072X-6-5

7. Burkle FM, Dallas CE. Developing a Nuclear Global Health Workforce AMID the increasing threat of a nuclear crisis. Disaster Med Public Health Prep (2015) 9:16. doi:10.1017/dmp.2015.125

8. Medvedev Z. The Legacy of Chernobyl. New York: W.W. Norton \& Co. (1990).

9. Terrorism Survey: Frequency Questionnaire. Washington, DC: Foreign Policy, Center for American Progress (2006).

10. Dallas CE, Bell W, Stewart D, Caruso A, Burkle FM. Nuclear war between Israel and Iran: lethality beyond the pale. Confl Health (2013) 7:10. doi:10.1186/1752-1505-7-10

11. Qureshi K, Gershon RRM, Sherman MF, Straub T, Gebbie E, McCollum M, et al. Health care workers; ability and willingness to report to duty during catastrophic disasters. J Urban Health (2005) 82:378-88. doi:10.1093/jurban/jti086

12. Alexander G, Larkin G, Wynia M. Physicians preparedness for bioterorrisrim and other public health priortities. Acad Emerg Med (2006) 13:1238-41. doi:10.1111/j.1553-2712.2006.tb01655.x

13. Syrett JI, Benitez JG, Livingston WH III, Davis EA. Will emergency health care providers respond to mass casualty incidents? Prehosp Emerg Care (2007) 11:49-54. doi:10.1080/10903120601023388

14. Jasper E, Miller M, Sweeney B, Berg D, Feuer E, Reganato D. Preparedness of hospitals to respond to a radiological terrorism event as assessed by a full-scale exercise. J Public Health Manage Pract (2005) 11(Suppl 1):S11-6. doi:10.1097/00124784-200511001-00003

15. Dallas CE. Medical training for nuclear and radiological events: the atomic age returns.DisasterMed Public Health Prep (2013) 7:441-2. doi:10.1017/dmp.2013.103

16. Brody AS, Guillerman RP. Don't let radiation scare trump patient care: 10 ways you can harm your patients by fear of radiation-induced cancer from diagnostic imaging. Thorax (2014) 69(8):782-4. doi:10.1136/thoraxjnl-2014-205499

\section{AUTHOR CONTRIBUTIONS}

CD: overall composition of manuscript, survey design, distribution, and analysis. KK: survey design, distribution and analysis, manuscript revision. TL: survey distribution and analysis. TK: survey design, distribution, and analysis. $\mathrm{CH}$ : survey design, distribution and analysis, and manuscript revision. RS: survey design, distribution and analysis, and manuscript revision.

\section{FUNDING}

This research was supported by University of Georgia Residual Funds FY17 1031RX792950.

17. Dallas CE, Burkle FM. Nuclear war in the Middle East: where is the voice of medicine and public health? Prehosp Disaster Med (2011) 26(5):383-5. doi:10.1017/S1049023X11006613

18. Mettler FA Jr. Medical resources and requirements for responding to radiological terrorism. Health Phys (2005) 89(5):488-93. doi:10.1097/01. HP.0000172143.37040.bd

19. Smith JM, Ansari A, Harper FT. Hospital management of mass radiological casualties: reassessing exposures from contaminated victims of an exploded radiological dispersal device. Health Phys (2005) 89(5):513-20. doi:10.1097/01 HP.0000175444.30788.75

20. Katz SK, Parrillo SJ, Christensen D, Glassman ES, Gill KB. Public health aspects of nuclear and radiological incidents. Am J Disaster Med (2014) 9(3):183-93. doi:10.5055/ajdm.2014.0170

21. Abrams HL. Medical survivors of nuclear war: infection and the spread of communicable disease. N Engl J Med (1981) 305:1226-32. doi:10.1056/ NEJM198111123052027

22. Dallas CE, Bell WC. Effects of a 10-kt IND Detonation on Human Health and the Area Health Care System: Effects on the Area Health Care System. Assessing Medical Preparedness to Respond to a Terrorist Nuclear Event. Washington, DC: Institute of Medicine of the National Academy of Science, The National Academies Press (2009). p. 20-6.

23. Sell TK. Rad Resilient City: A Preparedness Checklist to Save Lives after a Nuclear Detonation. Center for Biosecurity of UPMC (2013). Available from: http://www.upmchealthsecurity.org/our-work/pubs_archive/pubs-pdfs/2011/ rrc_mtg_rpt.pdf

24. WHO. Effect of Nuclear War on Health and Human Services. 2nd ed. Geneva: World Health Organization (1987).

25. Clark R, Ehrlich A, Gunn SWA. London Under Attack. Report of the Greater London Area War Risk Study (GLAWARS) Commission. Oxford, UK: Blackwell Scientific (1986).

26. U.S. Centers for Disease Control and Prevention (CDC). Types of Radiation Emergencies (2017). Available from: https://emergency.cdc.gov/radiation/ typesofemergencies.asp, and Radiation Training, https://emergency.cdc.gov/ radiation/training.asp

27. U.S. Department of Health and Human Services (HHS). Radiation Emergency Medical Management (REMM) (2017). Available from: https://www.remm nlm.gov

Conflict of Interest Statement: The authors declare that the research was conducted in the absence of any commercial or financial relationships that could be construed as a potential conflict of interest.

The reviewer, $\mathrm{PH}$, and the handling editor declared their shared affiliation, and the handling editor states that the process nevertheless met the standards of a fair and objective review.

Copyright (c) 2017 Dallas, Klein, Lehman, Kodama, Harris and Swienton. This is an open-access article distributed under the terms of the Creative Commons Attribution License (CC BY). The use, distribution or reproduction in other forums is permitted, provided the original author(s) or licensor are credited and that the original publication in this journal is cited, in accordance with accepted academic practice. No use, distribution or reproduction is permitted which does not comply with these terms. 